\title{
Cryptic diversity and signs of mitochondrial introgression in the Agrilus viridis species complex (Coleoptera: Buprestidae)
}

\author{
Mikko PENTINSAARI ${ }^{1}$, MARKo MUTANEN ${ }^{1}$ and LAURI KAILA ${ }^{2}$ \\ ${ }^{1}$ Department of Biology, P.O. Box 3000, FIN-90014 University of Oulu, Finland; e-mails: mikko.pentinsaari@oulu.fi; \\ marko.mutanen@oulu.fi \\ ${ }^{2}$ Finnish Museum of Natural History, Zoology Unit, P.O. Box 17, FI-00014 University of Helsinki, Finland; \\ e-mail: lauri.kaila@helsinki.fi
}

Key words. Coleoptera, Buprestidae, Agrilus, DNA barcoding, geometric morphometrics, cryptic diversity, mitochondrial introgression

\begin{abstract}
The jewel beetle genus Agrilus (Buprestidae), with approximately 2880 recognized species, is taxonomically challenging due to the great similarity of species. An example of taxonomic ambiguity is the Agrilus viridis species group, particularly the viridis complex that comprises many varieties differing both ecologically and morphologically. The status of these varieties has remained largely unresolved and no consensus exists on their status. We used geometric morphometrics in combination with the DNA barcode marker sequence in order to evaluate the possible distinction among populations of A. viridis feeding on Alnus, Betula and a variety of Salix species in Finland. We found that morphology supports the existence of two species, one feeding on Betula and Alnus, the other feeding on Salix. The findings based on DNA barcodes are more complex, suggesting possible introgression events in the species' history. Our results suggest that the Betula/Alnus and Salix feeding forms of A. viridis represent distinct species that have, while maintaining their morphological integrity, probably experienced repeated hybridization events in the past. DNA barcoding provides valuable additional information for taxonomic studies based on careful morphological study and information on their ecology, but drawing taxonomic conclusions from barcode data alone can lead to considerable confusion.
\end{abstract}

\section{INTRODUCTION}

Since the establishment of binomial nomenclature and modern taxonomy by Carolus Linnaeus in the 1750s, more than 1.5 million eukaryotic species have been described. However, the majority of extant species still await discovery and description. Estimates of the total number of species vary from 3.6 million to 100 million or even more (Wilson, 2003). Until recently, species delimitation was largely based on subjective visual evaluation and linear measurements of morphological characters. As DNA sequencing has become easier and cheaper, using sequence data in taxonomic work has become more and more frequent.

After the initial proposition of Hebert et al. (2003) to use $\mathrm{a} \sim 650 \mathrm{bp}$ fragment of the mitochondrial COI gene as a universal "barcode" for identification and possibly even species delimitation in animals, DNA barcoding has become a massive global enterprise targeting almost all living organisms. Generally, within-species variation in DNA barcodes is significantly smaller than the divergence between species (Hebert et al., 2003; Ward et al., 2005; Smith et al., 2006). DNA barcodes frequently reveal cryptic diversity even in regions and taxa with a long taxonomic tradition (Segerer et al., 2010; Mutanen et al., 2012a, b). However, several authors have also observed incongruence between species delimitations derived from barcode sequences and those based on other evidence (Monaghan et al., 2005; Astrin et al., 2012) and a notable increase in variation within species with increasing geographical scale (Bergsten et al., 2012).

Animal DNA barcodes also provide insights into mitochondrial genome evolution, e.g. by revealing traces of past introgression events. Introgression may obscure taxonomic resolution as it may yield deep intraspecific splits in gene trees and hence cause species to appear paraphyletic or polyphyletic. Such confounding patterns are best elucidated by examining other sets of characters, like nuclear markers and/or morphology.

Geometric morphometrics is a statistical approach for studying morphological shape based on coordinates of landmarks (Bookstein, 1991; Rohlf \& Marcus, 1993). Kendall's (1977) definition of shape as "all the geometrical information that remains when location, scale and rotational effects are filtered out from an object" and the distinction of shape from size are central to geometric morphometrics. In taxonomy, characters of shape are often considered more useful than traits measuring size, which are usually highly correlated with an individual's body size (Mutanen et al., 2006). Size may also be more evolutionarily labile than shape as it has been shown that bivalve shell shape can be stable over millions of years although size fluctuates (Stanley \& Yang, 1987) and that variation in resource availability may have a much greater effect on size than the shape of Drosophila wings (Breuker et al., 2006).

Traditionally, taxonomists have used subjective visual examination of morphological characters, and often also linear distance measurements, their ratios, as well as angles 
and other types of measures ("traditional morphometrics"), when describing differences and similarities between taxa. The main problems with traditional morphometrics are that it does not enable the complete separation of size from the shape (Rohlf \& Marcus, 1993) and does not preserve the geometric relationships between the points used for the distance measurements. The use of geometric morphometrics allows one to study size and shape separately and easily test the effect of size on shape. The size variable used in geometric morphometrics, called centroid size, is defined as the square root of the sum of squared distances from each landmark to the centroid, i.e. the geometric midpoint of the landmark configuration studied. As demonstrated by Mutanen \& Pretorius (2007), using geometric morphometric methods reduces the subjectivity of morphology-based identifications and species delimitation. The observed morphological differences can also be easily visualized using thin-plate splines or other types of shape diagrams. Geometric morphometrics is, therefore, an excellent tool for testing whether morphological evidence supports taxonomic hypotheses suggested by molecular or ecological data.

Agrilus Curtis 1825 is taxonomically a very challenging genus of buprestid beetles due to the large number of species (approx. 2880; Bellamy, 2012) and their considerable morphological similarity. In Europe, probably the best-known example of taxonomic ambiguity in this genus is the $A$. viridis (Linnaeus 1758) species group, particularly the viridis complex that comprises many varieties differing both in their ecology and morphology. The possible species status of these varieties has been suggested or speculated by e.g. Brechtel \& Kostenbader (2002) and studied by Bernhard et al. (2005). In general, species of Agrilus are monophagous or at most oligophagous (Bílý, 1982; Brechtel \& Kostenbader, 2002). A. viridis, however, has been recorded from a variety of different tree species. Many of these records are probably erroneous and due to misidentifications (Hellrigl, 1978). Records deemed reliable have been made from Salix, Fagus, Alnus, Betula, Carpinus, Corylus, Castanea, Acer and Tilia in Central
Europe (Hellrigl, 1978). This, and the observations that there are morphological differences between varieties of A. viridis feeding on different host plants (Alexeev, 1969; Bílý, 1982; Brechtel \& Kostenbader, 2002), gives reason to suspect that $A$. viridis may be a complex of closely related species rather than a single, variable, polyphagous species.

Our goal was to assess the possible species status of the willow- and birch-feeding varieties of $A$. viridis. We examined patterns of morphological and mitochondrial variation using geometric morphometrics and DNA barcoding. To scale the observed variation patterns in a wider context, we included two taxonomically well-established species in our morphometric analyses: A. paludicola Krogerus 1922, a close relative of $A$. viridis feeding on Betula nana L., and the more distantly related $A$. sulcicollis Lacordaire 1835 that feeds on Quercus spp. Two specimens of $A$. betuleti (Ratzeburg 1837), one A. subauratus Gebler 1833, one $A$. pratensis (Ratzeburg 1837) (= robertii Chevrolat 1838) and one A. suvorovi Obenberger 1935 (= populneus Schaefer 1946) were also barcoded. Due to shortage of additional material for these species, we did not include them in the morphometric analyses. One $A$. viridis specimen collected from Latvia on Salix viminalis L. was also included in our barcode tree.

\section{MATERIAL AND METHODS}

\section{Collecting and rearing}

All Finnish specimens of $A$. viridis and A. sulcicollis were reared from their larval host plants at several localities. The Betula variety of $A$. viridis was also found on Alnus incana (L.) Moench at the same locality in Juva where it occurred in great numbers on Betula. Colonized trunks and branches of Salix phylicifolia L., S. caprea L., S. glauca L., Betula spp., Alnus incana and Quercus robur L. were collected in the spring or early summer in 2005-2008 (for details, see Table 1) and put in plastic containers covered with gauze. The adult specimens that emerged were preserved in ethanol. All A. paludicola specimens (except for two specimens collected in the field for DNA extraction) were borrowed from the entomological collection of the Zoological Museum, University of Oulu. As none of the species involved are protected by law in Finland, no special permits for collecting

TABLE 1. Material studied. For more details, see supplementary Table S2.

\begin{tabular}{|c|c|c|c|c|c|}
\hline Species & Host plant & Locality & $\begin{array}{c}\text { Total number of } \\
\text { specimens studied }\end{array}$ & $\begin{array}{l}\text { Number of specimens used } \\
\text { in morphometric analyses }\end{array}$ & $\begin{array}{l}\text { Number of specimens } \\
\text { barcoded (successfully) }\end{array}$ \\
\hline \multirow[t]{8}{*}{ Agrilus viridis } & Alnus incana & Juva & 4 & 4 & $4(4)$ \\
\hline & Betula spp. & Juva & 37 & 37 & $15(14)$ \\
\hline & & Kiiminki & 3 & 3 & $3(3)$ \\
\hline & & Parainen & 4 & 4 & 0 \\
\hline & Salix caprea & Tornio & 16 & 16 & $10(10)$ \\
\hline & & Parainen & 4 & 4 & 0 \\
\hline & Salix phylicifolia & Kiiminki & 37 & 37 & $10(8)$ \\
\hline & Salix glauca & Kolari & 10 & 10 & $9(5)$ \\
\hline Agrilus sulcicollis & Quercus robur & Turku & 8 & 8 & $1(0)$ \\
\hline Agrilus paludicola & Betula nana & various & 35 & 35 & $3(0)$ \\
\hline Agrilus betuleti & Betula pendula & Juva \& Salo & 2 & 0 & $2(2)$ \\
\hline Agrilus suvorovi & Populus tremula & Nybro & 1 & 0 & $1(1)$ \\
\hline Agrilus pratensis & Populus tremula & Vihti & 1 & 0 & $1(1)$ \\
\hline Agrilus subauratus & Salix caprea & Lappeenranta & 1 & 0 & $1(1)$ \\
\hline
\end{tabular}




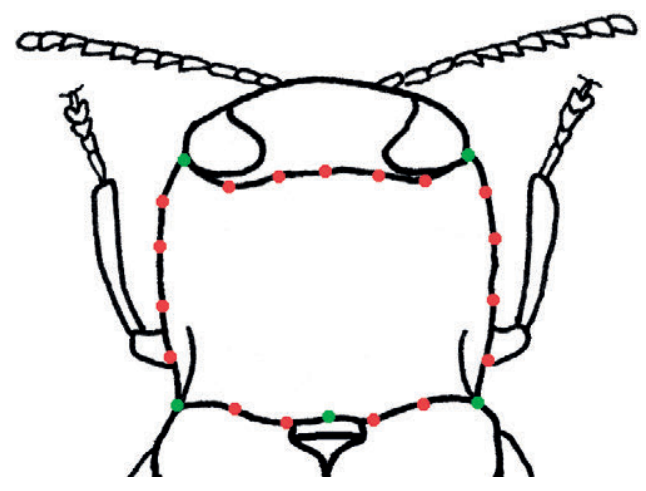

Fig. 1. Fixed landmarks (green) and sliding semi-landmarks (red) digitized on the pronotum. Redrawn from Bílý, 1982.

were required. Full details of the specimens studied, including locality data, GenBank accession numbers etc., are provided in supplementary Table S2.

\section{Specimen preparation and photography}

The number of specimens per species or population used in the morphometric analyses is shown in Table 1. The genitalia of all male specimens of $A$. viridis and $A$. paludicola were dissected

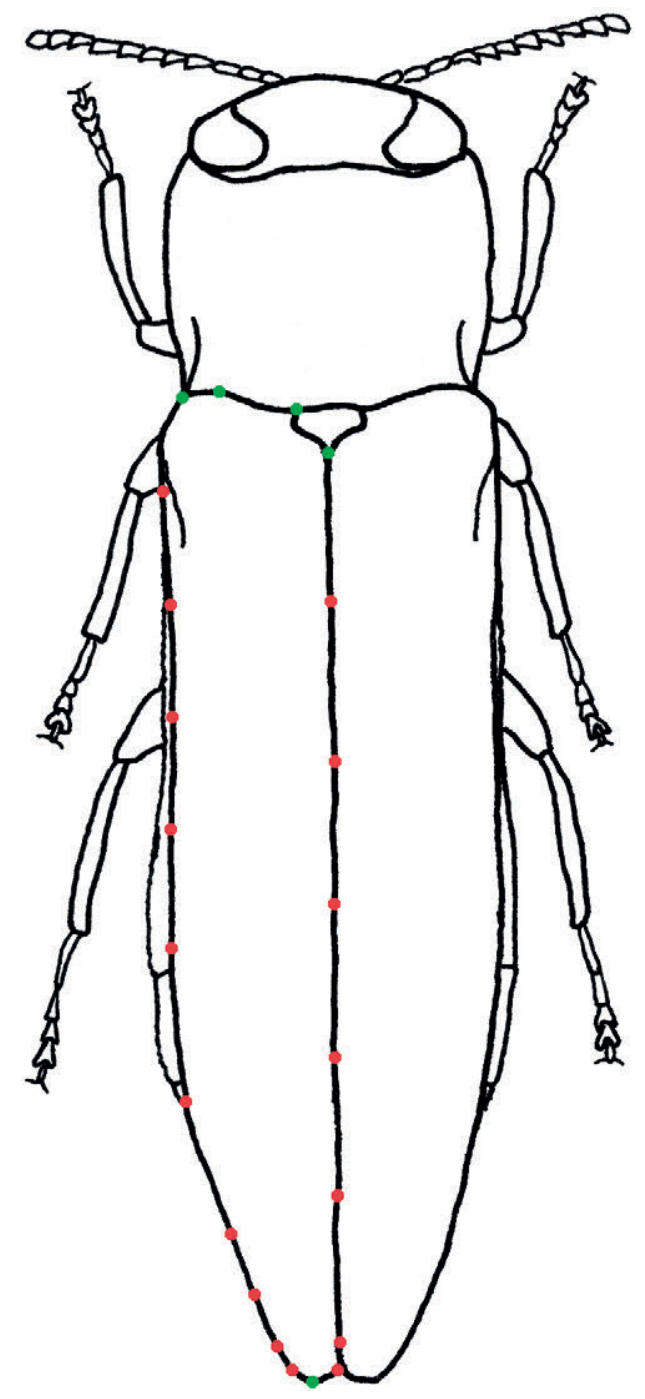

Fig. 2. Fixed landmarks (green) and sliding semi-landmarks (red) digitized on the left elytron. Redrawn from Bílý, 1982.
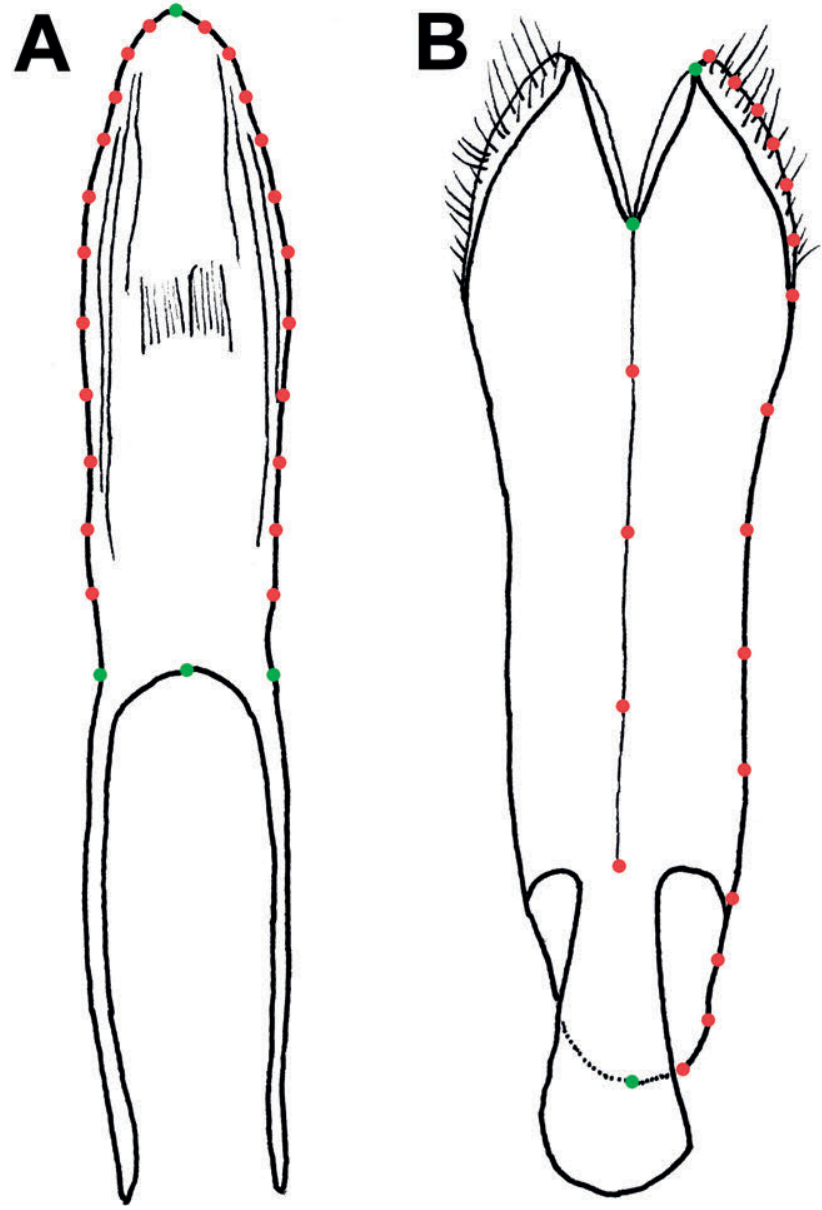

Fig. 3. Fixed landmarks (green) and sliding semi-landmarks (red) digitized on the male genitalia. A - penis, B - paramere.

and mounted in Euparal on microscope slides. The soft sutures between the sternites and tergites of the two last visible abdominal segments were cut and the genitalia and tissues surrounding them removed. The genitalia were then boiled in $10 \%$ potassium hydroxide for a couple of minutes in order to dissolve soft tissues. The penis and the parameres were separated, stained with Eosin gelblich and mounted under separate cover glasses on the same microscope slide. The separation was made in order to reduce preparation and digitizing errors. The penis of the taxa studied is relatively flat while the surrounding structure formed by the conjoined parameres is more three-dimensional and dorsoventrally curved.

The specimens' external structures were photographed using an Olympus Camedia C-7070 digital camera attached to an Olympus SZ30 stereo microscope. The reared specimens were placed on a piece of polystyrene and supported with insect pins so that they could be photographed straight from above with minimal distortion. The mounted specimens borrowed from collections were pinned on a piece of polystyrene so that the specimen could be seen straight from above and photographed using the microscope and camera arrangement described above. The male genitalia were photographed using the same camera attached to an Olympus $\mathrm{CH}-2$ microscope.

\section{Landmark selection and digitizing}

The external structures selected for morphometric analyses were the pronotum and the left elytron as they are particularly variable within A. viridis (Bílý, 1982). On the pronotum, we selected the anterior and posterior angles and the meeting point of 
TABLE 2. Cumulative proportion of variance explained by the first 20 principal component axes for each morphological structure.

\begin{tabular}{lcccc}
\hline & Pronotum & Elytron & Penis & Paramere \\
\hline PC1 & $62.76 \%$ & $34.39 \%$ & $71.50 \%$ & $42.08 \%$ \\
PC2 & $74.15 \%$ & $57.22 \%$ & $82.23 \%$ & $71.98 \%$ \\
PC3 & $83.34 \%$ & $72.47 \%$ & $87.45 \%$ & $80.12 \%$ \\
PC4 & $87.84 \%$ & $83.13 \%$ & $90.30 \%$ & $84.95 \%$ \\
PC5 & $90.36 \%$ & $87.07 \%$ & $92.71 \%$ & $88.75 \%$ \\
PC6 & $92.22 \%$ & $90.48 \%$ & $94.20 \%$ & $91.88 \%$ \\
PC7 & $93.54 \%$ & $92.46 \%$ & $95.31 \%$ & $93.82 \%$ \\
PC8 & $94.74 \%$ & $93.95 \%$ & $96.16 \%$ & $95.51 \%$ \\
PC9 & $95.61 \%$ & $95.20 \%$ & $96.87 \%$ & $96.84 \%$ \\
PC10 & $96.28 \%$ & $96.05 \%$ & $97.35 \%$ & $97.56 \%$ \\
PC11 & $96.85 \%$ & $96.84 \%$ & $97.74 \%$ & $98.14 \%$ \\
PC12 & $97.27 \%$ & $97.44 \%$ & $98.09 \%$ & $98.64 \%$ \\
PC13 & $97.66 \%$ & $97.93 \%$ & $98.38 \%$ & $98.95 \%$ \\
PC14 & $98.01 \%$ & $98.33 \%$ & $98.60 \%$ & $99.17 \%$ \\
PC15 & $98.28 \%$ & $98.64 \%$ & $98.79 \%$ & $99.35 \%$ \\
PC16 & $98.52 \%$ & $98.91 \%$ & $98.97 \%$ & $99.48 \%$ \\
PC17 & $98.74 \%$ & $99.16 \%$ & $99.12 \%$ & $99.61 \%$ \\
PC18 & $98.94 \%$ & $99.37 \%$ & $99.26 \%$ & $99.70 \%$ \\
PC19 & $99.13 \%$ & $99.53 \%$ & $99.38 \%$ & $99.77 \%$ \\
PC20 & $99.29 \%$ & $99.67 \%$ & $99.48 \%$ & $99.83 \%$ \\
\hline
\end{tabular}

the pronotum and the anterior corner of the scutellum as fixed landmarks (type II; Bookstein, 1991). The curved outlines between the fixed landmarks lack reliably repeatable landmark points so we used 17 evenly placed semi-landmarks (Bookstein, 1997) (Fig. 1). On the left elytron, the tip of the apex, the humeral angle and the posterior tip and left anterior angle of the scutellum were selected as fixed (type II) landmarks and the outlines between them were covered with 17 semi-landmarks (Fig. 2). The semi-landmarks were placed relatively densely at the elytral apex as its shape is often used as a diagnostic character in identifying Agrilus species (Lompe, 1979; Bílý, 1982).

We digitized four fixed landmarks on the penis and three on the parameres (Fig. 3.). The lateral landmarks at the base of the penis represent type III as their positions are defined based on the type II landmark at the basal notch of the penis. All other fixed genitalic landmarks are type II. Only the right side of the fused, symmetrical sheath-like structure formed by the parameres was digitized. Again, semi-landmarks were used to capture the shape of the curved outlines between the fixed landmarks (Fig. 3). The male genitalia of $A$. sulcicollis were excluded from morphometric analyses as they are highly asymmetric, unlike those of viridis and paludicola. The difference is immediately obvious to the naked eye and the shape differences among the much more uniform genitalia in the $A$. viridis group are more relevant to this study.

The landmarks were digitized using tpsDig 1.40 (Rohlf, 2004).

The pronotum and left elytron were digitized separately but the same image was used for both structures in each specimen. In some specimens, either the elytral apex or the genitalia were damaged and landmarks could not, therefore, be reliably digitized, but all other intact structures of these specimens were analyzed. The order of the specimens was randomized for each structure in order to avoid systematic digitization errors. To test the repeatability of landmark digitization, all genital images and a random subset of habitus images representing five specimens of both sexes of all taxa studied were digitized twice.
TABLE 3. Shape MANOVA.

\begin{tabular}{lcccr}
\hline Structure & Factor & Wilks' $\lambda$ & $\mathrm{F}$ & \multicolumn{1}{c}{$\mathrm{p}$} \\
\hline Pronotum & taxon & 0.0597 & 10.4204 & $<0.0001$ \\
& sex & 0.6602 & 1.5342 & 0.0265 \\
& taxon*sex & 0.7607 & 0.6364 & 0.9834 \\
Elytron & taxon & 0.1095 & 6.8452 & $<0.0001$ \\
& sex & 0.3608 & 4.1555 & $<0.0001$ \\
& taxon*sex & 0.5933 & 1.1915 & 0.1697 \\
Penis & taxon & 0.2661 & 2.1587 & 0.0013 \\
Paramere & taxon & 0.1774 & 2.9552 & $<0.0001$ \\
\hline
\end{tabular}

\section{DNA sampling and sequencing of the barcode region}

Total genomic DNA was extracted from the thoracic flight muscles of a subset of the Agrilus material (Table 1) using DNeasy ${ }^{\circledR}$ Blood \& Tissue kit by Qiagen according to the manufacturer's protocol. The COI DNA barcoding region was amplified and sequenced at the Canadian Centre for DNA Barcoding (University of Guelph, Guelph, ON, Canada) using their standard protocols (Ivanova \& Grainger, 2012a, b). The sequences were then uploaded into the Barcode of Life Datasystems (BOLD, http://www.boldsystems.org) where they are available as a public dataset (Title: Agrilus viridis complex, Finnish material; DOI: dx.doi.org/10.5883/DS-AVIRMP) along with photographs of the voucher specimens, collecting data and food plant information. The sequences are also available in GenBank (see the supplementary Table $\mathrm{S} 2$ for accession numbers).

\section{Morphometric and sequence analyses}

Procrustes superimposition removes the effects of size, scale and rotation from the shape data by centering each landmark configuration at the origin, scaling all configurations to unit centroid size and finally rotating all configurations so that the sum of squared distances between homologous landmarks is minimized between each configuration and the consensus (mean) shape calculated from all configurations. After the initial Procrustes superimposition where the semi-landmarks are treated as equal to true landmarks, the semi-landmarks are "slid" along a line tangent to the curve between the true landmarks at the respective semi-landmark positions to optimize their position along the curve (see Bookstein, 1997 or Zelditch et al., 2004, p. 399 for a more detailed description of this method). The Procrustes superimposition is recomputed after sliding the semi-landmarks, and the principal component analysis is based on this recomputed superimposition. We used tpsRelW 1.45 (Rohlf, 2007) to perform least squares Procrustes superimposition of landmarks and semilandmarks for each structure, to slide the semi-landmarks and calculate the principal component values of shape and centroid size of all morphological structures for each specimen. tpsRelW was also used for visualizing the shape differences between taxa with vector and thin plate spline images.

The difference in the shapes of each of the morphological structures of A. sulcicollis, A. paludicola and varieties of $A$. viridis studied was tested using multivariate analyses of variance (MANOVAs) with Wilks' lambda as the test statistic. Although the Salix- and Betula-feeding varieties of $A$. viridis have not been formally separated into different species, we treated them in our analyses as equal to the well-established paludicola and sulcicollis. If MANOVA indicated statistically significant differences between taxa, we used pairwise Hotelling's $\mathrm{T}^{2}$ tests for post hoc comparisons, with Bonferroni correction to control for multiple testing. The response variable in each MANOVA and subsequent Hotelling's tests was a matrix of 20 first principal components, 


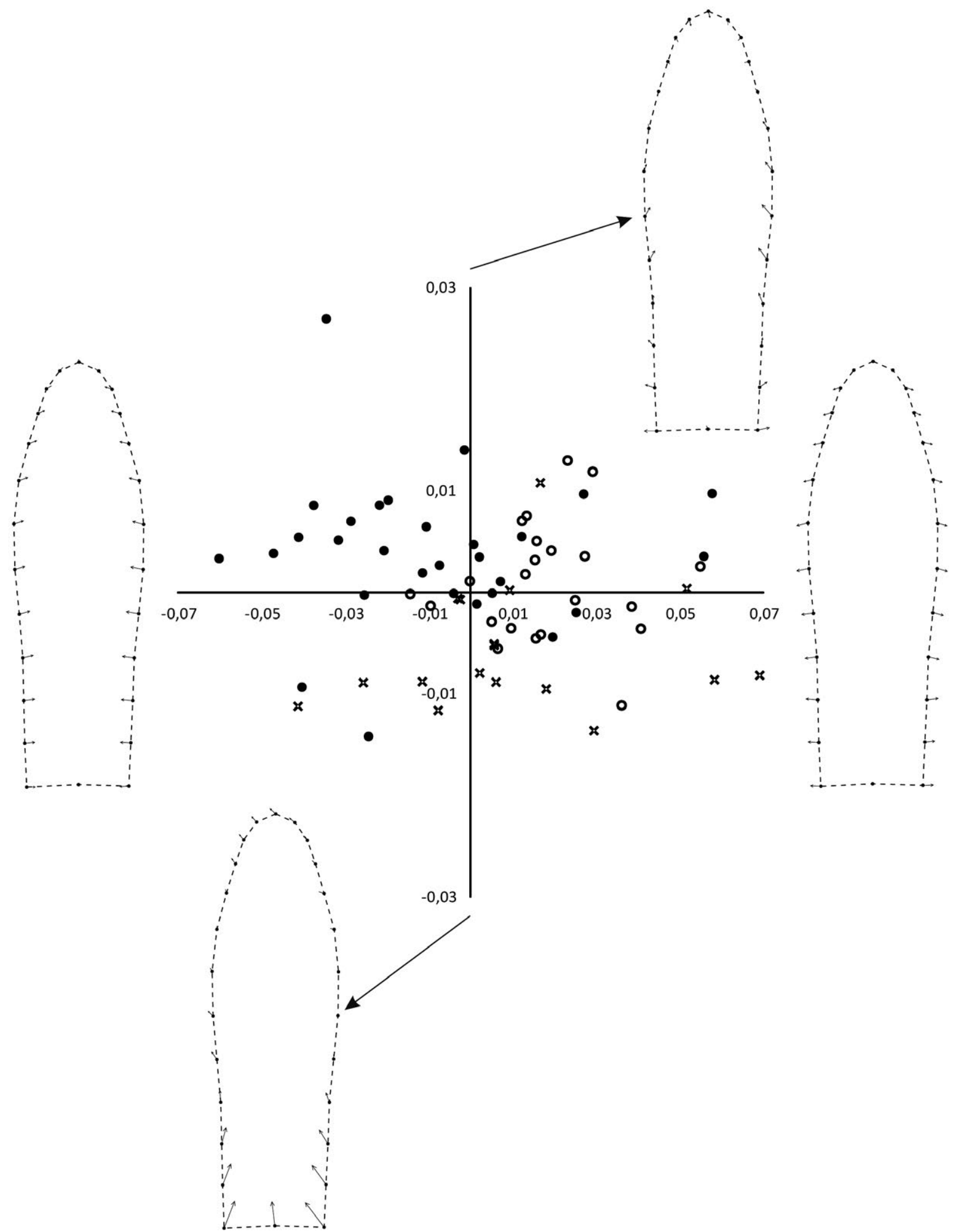

Fig. 4. Changes in the shape of the penis recorded along principal component axes 1 and 3 . Dots connected by dashes represent the consensus shape; changes in shape towards the ends of the axes are shown with vectors. Crosses - A. paludicola, filled circles - Salix variety of $A$. viridis, open circles - Betula variety of $A$. viridis.

which together explained more than $99 \%$ of all shape variation for each structure.

We also tested for size differences between the taxa studied in the four morphological structures using simple one-way ANOVAs for the genital structures and two-way ANOVAs with sex as the second factor besides taxon for external structures. Tukey's HSD test was used for post hoc comparisons when statistically significant differences between groups were detected. Hierarchical Procrustes ANOVA analyses as described by Viscosi \& Cardini (2011) were used to determine the proportion of variance in the data explained by digitization error. Klingenberg's (2011) MorphoJ software was used for these analyses. All other statistical analyses of morphometric data were made with $\mathrm{R}$ statistical software using the base packages included in the $\mathrm{R}$ distribution. 
TABLE 4. Centroid size ANOVA.

\begin{tabular}{lcccccc}
\hline Structure & Factor & df & SS & MS & F & $\mathrm{p}$ \\
\hline Pronotum & sex & 1 & 291110 & 291110 & 45.255 & $<0.0001$ \\
& taxon & 3 & 575510 & 191837 & 29.822 & $<0.0001$ \\
& sex*taxon & 3 & 18663 & 6221 & 0.967 & 0.41 \\
& residuals & 152 & 977772 & 6433 & & \\
Elytron & sex & 1 & 2170053 & 2170053 & 46.590 & $<0.0001$ \\
& taxon & 3 & 7807225 & 2602408 & 55.872 & $<0.0001$ \\
& sex*taxon & 3 & 201858 & 67286 & 1.445 & 0.2323 \\
& residuals & 144 & 6707221 & 46578 & & \\
Penis & taxon & 2 & 217808 & 108904 & 10.25 & 0.0001 \\
& residuals & 65 & 690715 & 10626 & & \\
Paramere & taxon & 2 & 1020612 & 510306 & 23.48 & $<0.0001$ \\
& residuals & 62 & 1347643 & 21736 & & \\
\hline
\end{tabular}

The first principal component axis is defined so that it explains as big a proportion of the total variation in the data as possible. The second PC axis is independent of the first and explains as much of the variation unexplained by the first axis, and so forth This is, however, not necessarily the most effective way to find differences between pre-defined groups, especially when differences between the groups are small and variation within groups is significant. Therefore, we used canonical variates analysis (CVA) of the principal component scores and centroid size to see if variation is truly discontinuous in the three closely related taxa studied. Jackknife or "leave-one-out" cross-validation was used in order to avoid the over-fitting issues associated with CVA (e.g. Kovarovic et al., 2011).

The sequence analyses were conducted using MEGA version 5 (Tamura et al., 2011). We calculated pairwise distances for all sequences using the Kimura 2-parameter model and constructed a Neighbour-Joining tree of all barcode sequences, with 100 bootstrap replicates.

\section{RESULTS}

\section{Shape and size}

The cumulative proportion of variance explained by the 20 first principal component axes for each morphological structure is shown in Table 2. Based on the MANOVA analysis, $A$. sulcicollis, $A$. paludicola and $A$. viridis specimens reared from Betula and Salix differed significantly from each other in terms of all four morphological structures studied (Table 3 ). Shape of the pronotum and elytron was significantly different between sexes. No significant interactions between sex and taxon were observed. Based on the subsequent pairwise Hotelling's $\mathrm{T}^{2}$ tests, the specimens reared from Betula and Salix differed from each other in terms of all the morphological structures studied, although the difference in penis shape was not significant after Bonferroni correction. As expected, the distantly re-
TABLE 6. Cross-validated CVA classification.

\begin{tabular}{|c|c|c|c|c|c|}
\hline \multirow[b]{2}{*}{ Structure } & \multirow[b]{2}{*}{ Sex } & \multirow[b]{2}{*}{ Taxon } & \multicolumn{3}{|c|}{ Predicted taxon } \\
\hline & & & paludicola & $\begin{array}{l}\text { viridis } \\
\text { (Salix) }\end{array}$ & $\begin{array}{c}\text { viridis } \\
\text { (Betula) }\end{array}$ \\
\hline \multirow[t]{3}{*}{ Penis } & & paludicola & 12 & 1 & 4 \\
\hline & & viridis (Salix) & 3 & 12 & 7 \\
\hline & & viridis (Betula) & 3 & 6 & 20 \\
\hline \multirow[t]{3}{*}{ Paramere } & & paludicola & 12 & 1 & 4 \\
\hline & & viridis (Salix) & 3 & 12 & 7 \\
\hline & & viridis (Betula) & 3 & 8 & 18 \\
\hline \multirow[t]{6}{*}{ Pronotum } & M & paludicola & 15 & 2 & 0 \\
\hline & & viridis (Salix) & 4 & 11 & 6 \\
\hline & & viridis (Betula) & 1 & 4 & 25 \\
\hline & $\mathrm{F}$ & paludicola & 13 & 3 & 2 \\
\hline & & viridis (Salix) & 4 & 12 & 10 \\
\hline & & viridis (Betula) & 3 & 8 & 29 \\
\hline \multirow[t]{6}{*}{ Elytron } & M & paludicola & 12 & 2 & 3 \\
\hline & & viridis (Salix) & 4 & 8 & 7 \\
\hline & & viridis (Betula) & 1 & 4 & 24 \\
\hline & $\mathrm{F}$ & paludicola & 17 & 1 & 0 \\
\hline & & viridis (Salix) & 1 & 9 & 12 \\
\hline & & viridis (Betula) & 3 & 5 & 31 \\
\hline
\end{tabular}

lated A. sulcicollis differed very significantly from all other taxa. A. paludicola also differed from all the other taxa. A complete summary of all pair wise tests is given in supplementary Table $\mathrm{S} 3$. The PC scores of the three focal taxa $(A$. paludicola and the two varieties of $A$. viridis) overlapped along all $\mathrm{PC}$ axes based on visual screening of the data. To provide an example, the PC 1 and PC 3 values calculated from the penis shape data, as well as the shape changes associated with these PC axes, are plotted in Fig. 4. The proportion of variance explained by digitization error was $2.6 \%$ for the pronotum, $2.1 \%$ for the elytron, $3.9 \%$ for the penis and $6.2 \%$ for the paramere.

In addition to differences in shape, we also found statistically significant differences in centroid size for all morphological structures (Table 4). Both the pronotum and elytron of A. paludicola were significantly smaller than those of all other taxa analyzed, and the elytron of $A$. sulcicollis was smaller than that of the two A. viridis varieties (not shown). No other significant pair wise differences in size were found in external structures. Females were on average larger than males in all taxa (apart from $A$. sulcicollis where the only male specimen studied was larger than the female average). Male genitalia of $A$. sulcicollis were excluded from the morphometric analysis (see above) so only the size differences between A. paludicola and the Salix-

TABLE 5. Post hoc test (Tukey's HSD) for pair wise differences in male genital size.

\begin{tabular}{lcccc}
\hline Structure & Taxon pair & Difference in means & $95 \%$ conf. interval & $\mathrm{p}$ \\
\hline Penis & viridis (Betula) - paludicola & $1484.55-1340.59=143.96$ & {$[64.11,223.80]$} & 0.0002 \\
& viridis (Salix) - paludicola & $1387.93-1340.59=47.34$ & {$[-28.18,122.87]$} & 0.2960 \\
& viridis (Salix) - viridis (Betula) & $1387.93-1484.55=-96.62$ & {$[-166.52,-26.71]$} & 0.0042 \\
Paramere & viridis (Betula) - paludicola & $2215.00-1881.77=333.23$ & {$[216.45,450.02]$} & $<0.0001$ \\
& viridis (Salix) - paludicola & $2065.36-1881.77=183.59$ & {$[74.74,292.44]$} & 0.0004 \\
& viridis (Salix) - viridis (Betula) & $2065.36-2215.00=-149.64$ & {$[-253.29,-45.99]$} & 0.0027 \\
\hline
\end{tabular}



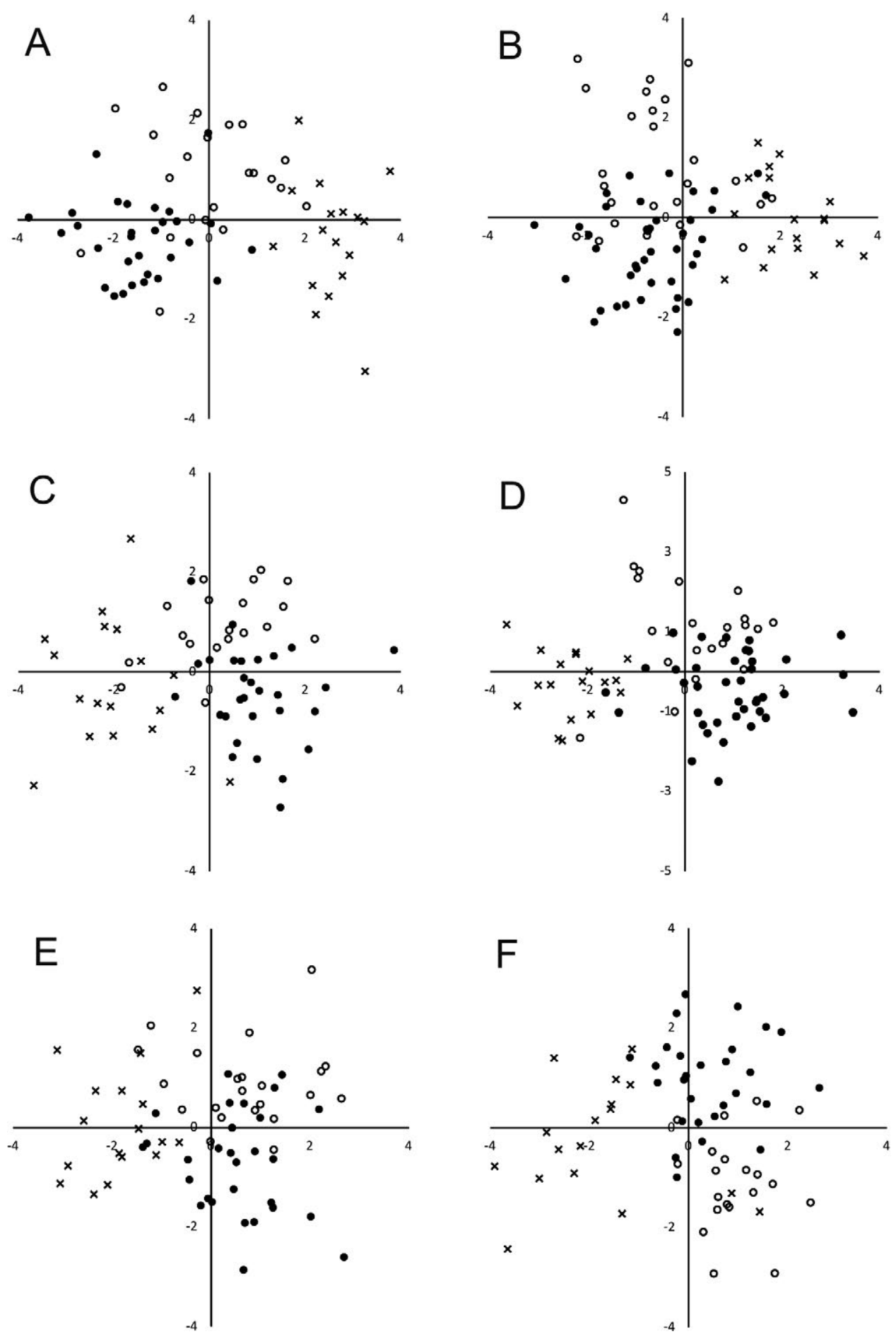

Fig. 5. Visualized results of the Canonical Variates Analysis of the Betula variety of A. viridis (open circles), Salix variety of $A$. viridis (filled circles) and A. paludicola (crosses). A - pronotum, males; B - pronotum, females; C - elytron, males; D - elytron, females; $\mathrm{E}$ - penis and $\mathrm{F}$ - paramere.

and Betula-varieties of $A$. viridis were tested. The post hoc test results for male genital size are shown in Table 5. The size of both penis and paramere is significantly different between the Salix- and Betula-varieties of A. viridis, with the Betula-variety having larger genitalia.

As there were significant differences in both shape and size between sexes, the CVA analyses for external characters were done separately for males and females. In the CVA ordinations, the separation of the three focal taxa is much more distinct than in PC scatterplots, although there is still some overlap between them (Fig. 5). The cross-validated classification tables based on the CVA analysis are shown in Table 6 for all structures. Notably large numbers of females of the Salix variety of $A$. viridis are misidentified as the Betula variety based on shape variables derived from external morphology. The proportion of correct classifications was higher for Salix variety males and much higher for A. paludicola and the Betula variety of $A$. viridis. 


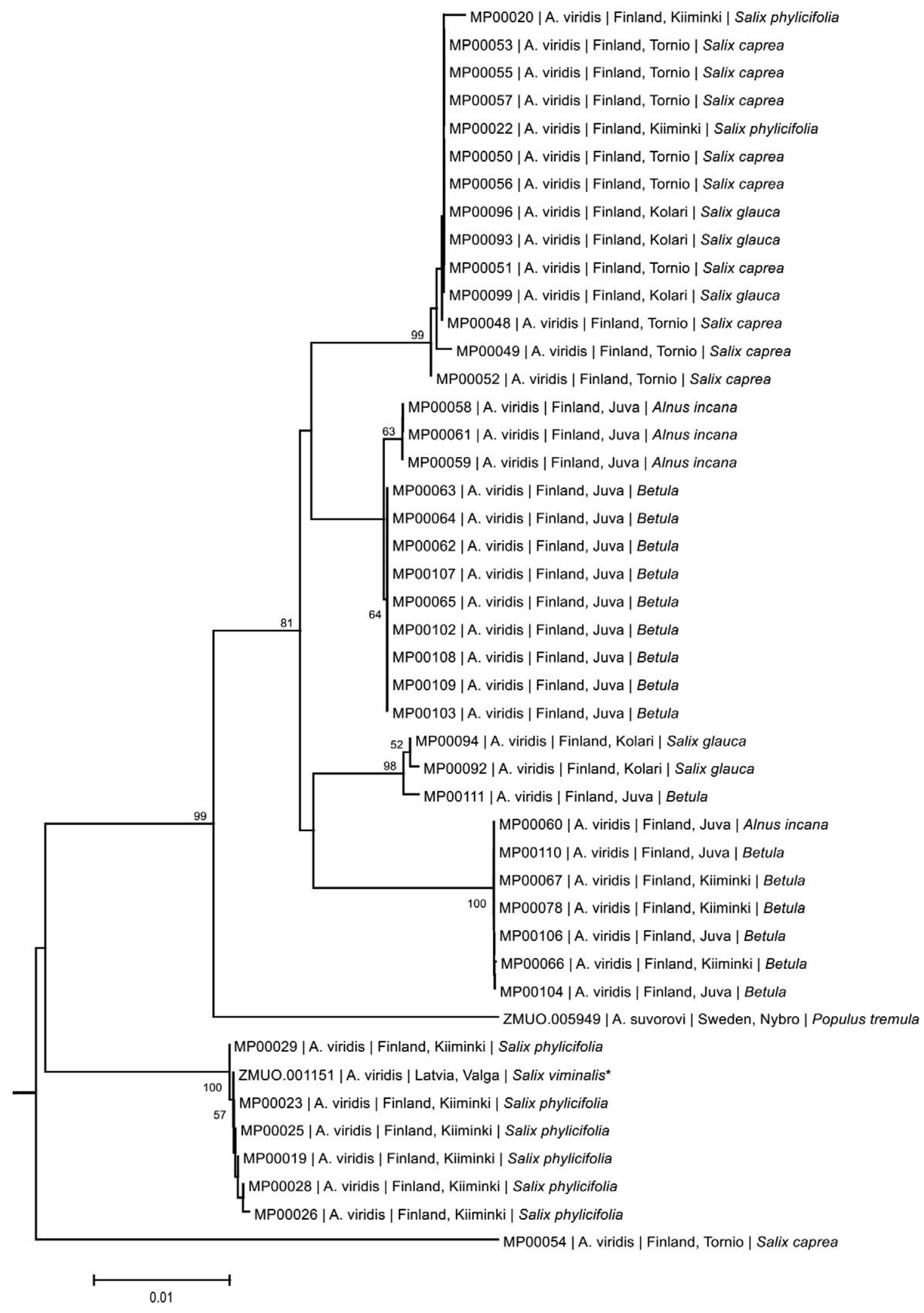

Fig. 6. NJ tree drawn from the Agrilus barcode sequences (only viridis and suvorovi shown). Bootstrap values of 50 or above are shown in the tree. The specimens are labelled as follows: BOLD sample ID $\mid$ Species name $\mid$ Locality $\mid$ host plant species. The tree was rooted with $A$. betuleti. *The Latvian specimen was not reared so the host plant is uncertain.

The Salix and Betula varieties of $A$. viridis differ from each other by their coloration as well as morphology. All specimens reared by us from Betula and Alnus are uni- colorous dark greenish, with a varying degree of bronze hue. Females of the Salix variety are typically bicolorous, with blue elytra and the rest of the body green to bluish 
TABLE 7. Summary of the genetic distances (Kimura 2-param.) within A. viridis.

\begin{tabular}{lccc}
\hline & min. distance & avg. distance & max. distance \\
\hline within A. viridis as traditionally defined & 0 & 0.023 & 0.070 \\
within the Betula-feeding variety & 0 & 0.012 & 0.023 \\
within the Salix-feeding variety & 0 & 0.025 & 0.068 \\
between Salix- and Betula-varieties & 0.002 & 0.027 & 0.070 \\
\hline
\end{tabular}

green. Salix variety males are mostly unicolorous, the colour varying from blue to green, but always much brighter than in the Betula variety.

\section{DNA barcodes}

Of the 60 Agrilus specimens sampled for DNA barcoding, 49 were barcoded successfully (Table 1). All specimens of A. betuleti, $A$. pratensis, $A$. subauratus, $A$. suvorovi and the majority of the $A$. viridis specimens produced good-quality barcodes. All three $A$. paludicola specimens and $A$. sulcicollis failed. The $\mathrm{K} 2 \mathrm{P}$ divergences between $A$. pratensis, $A$. betuleti, $A$. subauratus and the cluster containing all $A$. viridis sequences and $A$. suvorovi were $>20 \%$. A summary of the recorded genetic distances within $A$. viridis, as traditionally defined, and between various groups within $A$. viridis, is shown in Table 7.

In the Neighbour-Joining tree drawn from the barcoding sequences (Fig. 6, only viridis and suvorovi specimens shown), the specimens reared from Betula and Alnus form two major haplogroups without clustering according to the host plants or locality. In addition, one specimen reared from Betula clusters together with two northern specimens reared from Salix glauca. The rest of the specimens (except one) reared from different Salix species are divided into two major clusters. One of them forms a sister-group to the larger Betula-Alnus cluster and the other is quite clearly separated from both of these. The first cluster includes specimens reared form all three Salix species, the second is comprised of specimens reared from Salix phylicifolia and the Latvian specimen collected on Salix viminalis. One specimen, situated basally in our NJ tree and reared from Salix caprea, differs quite clearly from all others reared from the same host plant and locality (distance to most similar sequence 0.049 ). Interestingly, the $A$. suvorovi specimen also clusters within $A$. viridis, with a divergence of $3.4 \%$ from the most similar $A$. viridis sequences. As the divergences of $A$. betuleti, $A$. pratensis and $A$. subauratus from each other and the viridis complex were so high they were excluded from Fig. 6 to facilitate its interpretation. The complete NJ tree drawn from all retrieved Agrilus sequences is included as a supplementary Fig. S1.

\section{DISCUSSION}

The Salix and Betula-feeding varieties of $A$. viridis and other Agrilus species studied differed significantly from each other in terms of the shapes of all the morphological structures analyzed. The clear morphometric distinction of A. sulcicollis from other species studied was expected as the shape differences are obvious even to the naked eye. A. paludicola, on the other hand, belongs to the same taxonomically challenging species group as $A$. viridis. It nev- ertheless differed significantly from $A$. viridis in terms of both its external morphology and male genitalia.

Within A. viridis, the specimens reared from Betula and Alnus were similar in terms of morphology and coloration. The Alnus-feeding specimens were found at the same locality in Juva as the Betula-feeding specimens and are present in both major Betula variety barcode clusters. Betula and Alnus are closely related plant genera, so the occurrence of the Betula variety on Alnus is not unexpected and has been recorded in Central Europe (Brechtel \& Kostenbader, 2002). The Betula variety is closely related to $A$. viridis var. fagi (Ratzeburg, 1839) that lives exclusively on Fagus sylvatica L. (Brechtel \& Kostenbader, 2002). The Salix variety seems to be morphologically more variable and a high number of specimens are misclassified in our CVA analysis based on each of the morphological structures. However, it still differed significantly from the Betula variety in terms of both external and genital shape characters based on the MANOVA analyses. The significant difference in genital size between the two varieties is also worth noticing. The size of genital structures is most often negatively allometric to body size, i.e. genital size increases relatively little with increasing body size within species (Mutanen et al., 2006 and references therein). The Betula and Salix varieties of $A$. viridis had near-identical body size distributions based on centroid sizes of the pronotum and elytra, but the male genitalia were significantly bigger in the Betula variety (Table 5).

Based on morphology, coloration and food plant preferences, the Salix and Betula varieties of $A$. viridis can be considered to be two distinct species. However, neither the Salix variety nor the Betula variety appears monophyletic in the barcode tree. The COI barcodes of the willow-feeding specimens show several clearly defined haplogroups, the largest of which is more similar to the larger Betula variety haplogroup than other Salix variety haplogroups. However, the nodes connecting the four haplogroups in the cluster appearing as the sister group of $A$. suvorovi had rather low bootstrap support (39 and 45\%), so mitochondrial monophyly of the Betula variety is somewhat uncertain. The Salix variety is clearly non-monophyletic.

Monaghan et al. (2005) observed similar incongruence between morphological and molecular data, but on a much larger scale. Among Copelatus Erichson, 1832 diving beetles (Coleoptera: Dytiscidae) inhabiting the Fiji islands, they found 25 provisional species based on morphological data and 22 distinct genetic clusters. In only four cases were the morphological and genetic groupings completely congruent. The authors considered this to be due to both persistence of ancient polymorphisms and frequent hybridization during the radiation of Copelatus species. 
The divergence between the two major clusters of willow-feeding A. viridis is approximately $4 \%$. Often, when using the operational taxonomic unit or OTU approach to explore biodiversity, the cutoff value used to delimit provisional species has been 2-3\% sequence divergence (Blaxter, 2004; Smith et al., 2005). Mostly, OTU-based delimitation and morphology-based traditional taxonomy have yielded similar results (Smith et al., 2005; Smith \& Fisher, 2009). Based on barcodes alone, using a simple distance-based approach, the willow-feeding $A$. viridis would be divided into four OTUs. However, all of the willowfeeding populations we studied contained specimens belonging to two different barcode clusters. The single specimen (MP00054) with a barcode sequence different from all other willow-feeding specimens was reared from the same Salix caprea branches as the rest of the specimens sampled from Tornio and it does not differ morphologically in any way from the rest of the Salix-feeders. The two major clusters of the Betula variety show a divergence of about $2.3 \%$ and might be labelled as different OTUs depending on the cutoff value used.

DNA barcodes have been shown to be effective in species identification and even delimitation in various animal taxa, with more than $95 \%$ of taxa studied reliably identified and morphologically cryptic species often discovered (Hebert et al., 2004; Hajibabaei et al., 2006). Cases where barcode-based identification or delimitation has failed or barcode sharing between species has been observed are evidently due to hybridization or recent speciation (Hajibabaei et al., 2006, Kaila \& Ståhls, 2006). Introgression is reported to confuse barcode-based species identification to various extents in different animal groups (e.g. Whitworth et al., 2007; Smith et al., 2008).

Funk \& Omland (2003) reviewed the frequency and possible causes of species-level non-monophyly in animal mitochondrial gene trees. Apart from imperfect taxonomy, the most important reasons they list for mitochondrial paraphyly and polyphyly at species level are incomplete lineage sorting or historical polymorphism, and introgression through hybridization. Incomplete sorting and introgression are difficult to distinguish, but basal polyphyly in the gene tree hints at incomplete sorting. More recent introgression events are more likely to show up at derived positions in the tree (Funk \& Omland, 2003). Introgression through hybridization and/or preservation of historical polymorphism are, in our opinion, more likely causes for the confounding pattern observed in A. viridis barcodes than the existence of more than two species in our $A$. viridis data.

As a rule, species of Agrilus are monophagous or at most oligophagous (Bílý, 1982; Brechtel \& Kostenbader, 2002). However, they apparently have potential for host shifts (Bernhard et al., 2005). According to Janz \& Nylin (1998), the recolonization of an ancestral host plant has been more frequent than shifting to a completely new plant species in the evolutionary history of butterflies. If this is also the case in Agrilus, a possible explanation for our results is that the Betula variety of $A$. viridis has, after diverg- ing from the Salix variety, hybridized with it again. The small cluster including two specimens reared from Salix glauca (MP00092, MP00094) and one reared from Betula (MP00111) seems a good candidate for a relatively recent introgression event as the $\mathrm{K} 2 \mathrm{P}$ distance between their sequences is only about 0.002 . The rest of the branching events are not easily interpreted without additional data from nuclear loci.

In the tree constructed by Bernhard et al. (2005) from two mitochondrial loci, A. suvorovi appears as a sister group to a cluster including $A$. ribesi Schaefer and all varieties of $A$. viridis. In our barcode tree, in contrast, the only A. suvorovi sequence is found deep within $A$. viridis. $A$. suvorovi belongs to the same group of closely related species as $A$. viridis so mitochondrial introgression from viridis to suvorovi in these species' history is a realistic explanation of the pattern observed in our barcode tree. However, Bernhard et al. (2005) only sequenced three specimens of the Salix variety of $A$. viridis, two of which came from the same locality. If there is similar variation in other parts of A. viridis genome as in its barcode sequences, it would easily be missed by such restricted sampling.

The morphological differentiation between varieties of A. viridis was previously studied by Alexeev (1969). He examined specimens of $A$. viridis reared from Populus, Tilia, Ribes, Corylus, Fagus and Acer and noticed morphological differentiation between them in both external characters and male genitalia. We find it likely that his specimens from Populus in fact represent $A$. suvorovi and those found on Ribes probably belong to $A$. ribesi Schaefer 1946. Alexeev's observation that these "ecotypes" as he calls them can occur sympatrically and that their respective morphological characters are noticeable even in sympatric conditions supports our view that $A$. viridis consists of several species. Unfortunately, Alexeev did not include the Salix and Betula varieties of $A$. viridis in his study. Heering (1956a, b) made a thorough study of the development and behaviour of the variety of $\mathrm{A}$. viridis feeding on beech ( $\mathrm{Fa}$ gus sylvatica). He observed that the females of that variety rejected all other host plants offered (including Betula and Salix caprea) although in the laboratory they readily oviposited on beech. Although Heering did not perform similar food plant selection experiments on other varieties of A. viridis or attempt to cross-breed the different varieties, his results are indicative of their host plant specificity and ecological separation.

The Agrilus viridis group of species is phylogenetically young, and apparently in a state of radiation (Bílý, 1982; Bernhard et al., 2005). Bernhard et al. (2005) conclude that although the genetic divergence they observed between the varieties of $A$. viridis feeding on different plant species was low, the varieties appear to be genetically and ecologically separated and can be considered to be different species. Our results on the barcode sequences reveal more complexity within $A$. viridis, but we agree with Bernhard et al. (2005) in that the viridis host varieties are separate species. In addition to genetic and ecological separation, we observed that the willow and birch feeding varieties also 
differ in their morphology. Furthermore, the association between host plant, morphology and COI haplotypes and the differentiation between the viridis varieties is preserved when the forms are found in sympatry, as is the case at Kiiminki in northern Finland.

As no type material was studied, we cannot provide any solution to the questions of nomenclature within the A. viridis complex. In the Catalogue of Palearctic Coleoptera (Jendek, 2006) 25 names are listed as synonyms of $A$. viridis. Therefore, it is likely that many of the provisional species within this complex already have a name. More material from a wider geographical range and analysis of nuclear markers in addition to barcodes is needed to better understand the genetic relationships within the $A$. viridis group of species. Undoubtedly, a more thorough genetic study will facilitate a proper taxonomic revision of this species complex.

ACKNOWLEDGEMENTS. We wish to thank P. Martikainen, J. Vilén and J. Salokannel for providing part of the material used in this study. We are also grateful for the support provided by the Government of Canada through Genome Canada and the Ontario Genomics Institute to the International Barcode of Life Project. This funding enabled the Canadian Centre for DNA Barcoding (University of Guelph) to carry out the sequence analysis on our specimens. We also thank the Ontario Ministry of Economic Development and Innovation for funding the ongoing development of BOLD. This work was funded by personal grants to MP from Societas Biologica Fennica Vanamo, Societas pro Fauna et Flora Fennica, Oulun luonnonystäväin yhdistys, the Ella and Georg Ehrnrooth Foundation and the Jenny and Antti Wihuri Foundation. Two anonymous reviewers provided helpful comments on an earlier version of this manuscript.

\section{REFERENCES}

Alexeev A.V. 1969: [On food forms of the flat-headed pear-borer Agrilus viridis L. (Coleoptera, Buprestidae)]. - Zool. Zh. 48: 85-92 [in Russian with English abstr.].

Astrin J.A., Stüben P.E., Misof B., Wägele J.W., Gimnich F., RAUPACH M.J. \& Ahrens D. 2012:. Exploring diversity in cryptorhynchine weevils (Coleoptera) using distance-, character- and tree-based species delineation. - Mol. Phylogenet. Evol. 63: 1-14.

Bellamy C.L. 2012: Genus Agrilus Curtis 1825. A Checklist of World Buprestoidea. Available at: http://www.fond4beetles. com/Buprestidae/WorldCat/Genera/Agrilus.htm. Accessed 27 August 2012.

Bergsten J., Bilton D.T., Fujisawa T., Elliott M., Monaghan M.T., Balke M., Hendrich L., Geijer J., Herrmann J., Foster G.N., Ribera I., Nilsson A.N., Barraclough T.G. \& Vogler A.P. 2012: The effect of geographical scale of sampling on DNA barcoding. - Syst. Biol. 61: 851-869.

Bernhard D., Fritzsch G., Glöckner P. \& Wurst K. 2005: Molecular insights into speciation in the Agrilus viridis-complex and the genus Trachys (Coleoptera: Buprestidae). - Eur. J. Entomol. 102: 599-605.

BíLÝ S. 1982: The Buprestidae (Coleoptera) of Fennoscandia and Denmark. - Fauna Entomol. Scand. 10, 109 pp.

Blaxter M.L. 2004: The promise of a DNA taxonomy. - Phil. Trans. R. Soc. (B) 359: 669-679.

BooKsteIn F. 1991: Morphometric Tools for Landmark Data: Geometry and Biology. Cambridge University Press, New York, $456 \mathrm{pp}$.
BooksteIN F. 1997: Landmark methods for forms without landmarks: morphometrics of group differences in outline shape. - Med. Image Anal. 1: 225-244.

Brechtel F. \& Kostenbader H. 2002: Die Pracht- und Hirschkäfer Baden-Württembergs. Ulmer, Stuttgart, 632 pp.

Breuker C.J., Patterson J.S. \& Klingenberg C.P. 2006: A single basis for developmental buffering of Drosophila wing shape. — PLOS ONE 1(1): e7. doi:10.1371/journal.pone.0000007

FunK D.J. \& OMLAND K.E. 2003: Species-level araphyly and polyphyly: Frequency, causes, and consequences, with insights from animal mitochondrial DNA. - Annu. Rev. Ecol. Evol. Syst. 34: 397-423.

Hajibabaei M., Janzen D.H., Burns J.M., Hallwachs W. \& HeBERT P.D.N. 2006: DNA barcodes distinguish species of tropical Lepidoptera. - Proc. Natl. Acad. Sci. U.S.A. 103: 968-971.

Hebert P.D.N., Cywinska A., Ball S.L. \& deWaArd J. 2003: Biological identifications through DNA barcodes. - Proc. R. Soc. (B) 270: 313-321.

Hebert P.D.N., Penton E.H., Burns J.M., Janzen D.H. \& HallWACHS W. 2004: Ten species in one: DNA barcoding reveals cryptic species in the neotropical skipper butterfly Astraptes fulgerator. - Proc. Natl. Acad. Sci. U.S.A. 101: 14812-14817.

HeERING H. 1956a: Zur Biologie, Ökologie und zum Massenwechsel des Buckenprachtkafers (Agrilus viridis L.). I. Teil. Z. Angew. Entomol. 38: 249-287.

HeErIng H. 1956b: Zur Biologie, Ökologie und zum Massenwechsel des Buckenprachtkafers (Agrilus viridis L.). II. Teil. - Z. Angew. Entomol. 39: 76-114.

Hellrigl K.G. 1978: Ökologie und Brutpflanzen europäischer Prachtkäfer (Col., Buprestidae). Teil 2. - Z. Angew. Entomol. 85: 253-257.

Ivanova N. \& Grainger C. 2012a: CCDB Protocols: COI Amplification. Canadian Centre for DNA Barcoding. Available at: http://www.dnabarcoding.ca/CCDB_DOCS/CCDB_Amplification.pdf

Ivanova N. \& Grainger C. 2012b: CCDB Protocols: Sequencing. Canadian Centre for DNA Barcoding. Available at: http:// www.dnabarcoding.ca/CCDB_DOCS/CCDB_Sequencing.pdf

JANZ N. \& NyLIN S. 1998: Butterflies and plants: a phylogenetic study. - Evolution 52: 486-502.

JendeK E. 2006: Genus Agrilus. In Löbl I. \& Smetana A. (eds): Catalogue of Palearctic Coleoptera. Vol. 3. Apollo Books, Stenstrup, pp. 388-403.

KaILA L. \& STÅHLS G. 2006: DNA barcodes: Evaluating the potential of COI to diffentiate closely related species of Elachista (Lepidoptera: Gelechioidea: Elachistidae) from Australia. Zootaxa 1170: 1-26.

Kendall D.G. 1977: The diffusion of shape. - Adv. Appl. Probab. 9: 428-430.

KLINGenberg C.P. 2011: MorphoJ: an integrated software package for geometric morphometrics. - Mol. Ecol. Resour. 11: 353-357.

Kovarovic K., Aiello L.C., Cardini A. \& Lockwood C.A. 2011: Discriminant function analyses in archaeology: are classification rates too good to be true? - J. Archaeol. Sci. 38: 30063018.

Lompe A. 1979: Tribus Agrilini. In Freude H., Harde K.W. \& Lohse G.A. (eds): Die Käfer Mitteleuropas, Band 6: Diversicornia. Goecke \& Evers, Krefeld, pp. 230-243.

Monaghan M.T., Balke M., Pons J. \& Vogler A.P. 2005: Beyond barcodes: complex DNA taxonomy of a South Pacific Island radiation. - Proc. R. Soc. (B) 273: 887-893.

Mutanen M. \& Pretorius E. 2007: Subjective visual evaluation vs. traditional and geometric morphometrics in species delimi- 
tation: a comparison of moth genitalia. - Syst. Entomol. 32 371-386.

Mutanen M., Kaitala A. \& MönKkönen M. 2006: Genital variation within and between three closely related Euxoa moth species: testing the lock-and-key hypotheses. - J. Zool. (Lond.) 268: 109-119.

Mutanen M., Aarvik L., Landry J.F., Segerer A. \& Karsholt O. 2012a: Epinotia cinereana (Haworth, 1811) bona sp., a Holarctic tortricid distinct from E. nisella (Clerck, 1759) (Lepidoptera: Tortricidae: Eucosmini) as evidenced by DNA barcodes, morphology and life history. - Zootaxa 3318: 1-25.

Mutanen M., Aarvik L., Huemer P., Kaila L., Karsholt O. \& Tuck K. 2012b: DNA barcodes reveal that the widespread European tortricid moth Phalonidia manniana (Lepidoptera: Tortricidae) is a mixture of two species. - Zootaxa 3262: 1-21.

RoHLF F.J. 2004: tpsDig, version 1.40. Department of Ecology and Evolution, State University of New York at Stony Brook. Available: http://life.bio.sunysb.edu/morph/softdataacq.html

RoHLF F.J. 2007: tpsRelw, version 1.45. Department of Ecology and Evolution, State University of New York at Stony Brook. Available: http://life.bio.sunysb.edu/morph/soft-tps.html

RoHLF F.J. \& MARCUS L.F. 1993: A revolution in morphometrics. — Trends Ecol. Evol. 8: 129-132.

Segerer A.H., Haslberger A. \& Grünewald T. 2010: Olethreutes subtilana (Falkovich, 1959): Unexpected occurrence of an 'eastern' leaf roller in Central Europe, uncovered by DNA barcoding (Tortricidae: Olethreutinae). — Nota Lepidopterol. 33: 197-206.

SMith M.A. \& Fisher B.L. 2009: Invasions, DNA barcodes, and rapid biodiversity assessment using ants of Mauritius. Front. Zool. 6: 31.

SMith M.A., Fisher B.L. \& HeberT P.D.N. 2005: DNA barcoding for effective biodiversity assessment of a hyperdiverse arthropod group: the ants of Madagascar. - Phil. Trans. R. Soc. (B) 360: $1825-1834$.

Smith M.A., Woodley N.E., Janzen D.H., Hallwachs W. \& HeBERT P.D.N. 2006: DNA barcodes reveal cryptic host-specificity within the presumed polyphagous members of a genus of parasitoid flies (Diptera: Tachinidae). - Proc. Natl. Acad. Sci. U.S.A. 103: 3657-3662.

Smith M.A., Poyarkov N.A. \& Hebert P.D.N. 2008: CO1 DNA barcoding amphibians: take the chance, meet the challenge. Mol. Ecol. Resour. 8: 235-246.

StANLEY S.M. \& YANG X. 1987: Approximate evolutionary stasis for bivalve morphology over millions of years: A multivariate, multilineage study. - Paleobiology 13: 113-139.

Tamura K., Peterson D., Peterson N., Stecher G., Nei M. \& KumAR S. 2011: MEGA5: Molecular evolutionary genetics analysis using maximum likelihood, evolutionary distance, and maximum parsimony methods. - Mol. Biol. Evol. 28: 2731-2739.

Viscosi V. \& CARDINI A. 2011: Leaf morphology, taxonomy and geometric morphometrics: A simplified protocol for beginners. - PLoS One 6: e25630.

Ward R.D., Zemlak T.S., Innes B.H., Last P.R. \& Hebert P.D.N. 2005: DNA barcoding Australia's fish species. - Phil. Trans. R. Soc. (B) 360: 1847-1857.

Whitworth T.L., Dawson R.D., Magalon H. \& Baudry E. 2007: DNA barcoding cannot reliably identify species of the blowfly genus Protocalliphora (Diptera: Calliphoridae). - Proc. R. Soc. (B) 274: 1731-1739.

WiLson E.O. 2003: The encyclopedia of life. - Trends Ecol. Evol. 18: 77-80.

Zelditch M.L., Swiderski D.L., Sheets H.D. \& Fink W.L. 2004: Geometric Morphometrics for Biologists: a Primer. Elsevier Academic Press, San Diego, 443 pp.

Received January 21, 2014; revised and accepted May 30, 2014 Prepublished online August 19, 2014

Supplementary files:

S1 (http://www.eje.cz/2014/072/S01.pdf). NJ tree of all barcoded Agrilus specimens.

S2 (http://www.eje.cz/2014/072/S02.xlsx). Collection and storage data on the specimens studied and GenBank accession numbers of the barcode sequences.

S3 (http://www.eje.cz/2014/072/S03.xlsx). Summary of Hotelling's T2 tests used for pairwise shape comparisons between taxa. 